\title{
Questões para o trabalho profissional do Assistente Social no processo transexualizador
}

Pablo Cardozo Rocon ${ }^{1}$

https://orcid.org/0000-0003-2696-5786

Marco José de Oliveira Duarte ${ }^{2,3}$

https://orcid.org/0000-0002-6395-1941

\author{
Francis Sodré ${ }^{4}$ \\ https://orcid.org/0000-0003-4037-9388
}

\footnotetext{
${ }^{1}$ Universidade Federal de Mato Grosso, Instituto de Saúde Coletiva, Cuiabá, MT, Brasil

${ }^{2}$ Universidade Federal de Juiz de Fora, Faculdade de Serviço Social, Programa de Pós-Graduação em Serviço Social, Juiz de Fora, MG, Brasil

${ }^{3}$ Universidade do Estado do Rio de Janeiro, Faculdade de Serviço Social, Programa de Pós-Graduação em Serviço Social, Rio de Janeiro, RJ, Brasil

${ }^{4}$ Universidade Federal do Espírito Santo, Departamento de Serviço Social, Programa de Pós-Graduação em Saúde Coletiva, Vitória, ES, Brasil
}

\section{Questões para o trabalho profissional do Assistente Social no processo transexualizador}

Resumo: Reflete-se as possibilidades ao trabalho profissional dos(as) assistentes sociais no processo transexualizador brasileiro a partir de uma pesquisa documental em resoluções e dispositivos ético-políticos produzidos pelo Serviço Social brasileiro. Aponta-se a defesa do nome social, a luta contra trans-travestifobia, o trabalho com as famílias, com as redes sócioassistenciais e a construção da consciência sanitária, como rico campo para intervenção profissional nesse programa. Conclui-se que apesar de não haver uma nota técnica que norteie o trabalho profissional nesse programa, as orientações para o trabalho profissional junto à população trans no Sistema Único de Saúde encontram-se no conjunto do Projeto Ético-Político Profissional.

Palavras-chave: Transexualidade. Gênero. Sexualidade. Trabalho profissional. Serviço Social.

\section{Issues faced by Social Workers in the transsexualization process}

Abstract: This article reflects on the possibilities for social workers in the Brazilian transsexualization process based on a documentary research in resolutions and ethical-political devices produced by the Brazilian Social Work. We discuss here the social name defense, the struggle against transvestiphobia, work with the families, the social assistance networks and the construction of the health conscience, as a rich field for professional intervention in this program. The conclusion is that although there is no specific technical note to offer a reference for the social workers practice in this program, the guidelines for professional work with the transgender population provided in the National Health System (SUS) are included in the Professional Ethical-Political Project.

Keywords: Transsexuality. Genre. Sexuality. Professional work. Social Work.

Recebido em 25.09.2017. Aprovado em 25.05.2018. Revisado em 22.06.2018.

(C) O(s) Autor(es). 2018 Acesso Aberto Esta obra está licenciada sob os termos da Licença Creative Commons Atribuição-NãoComercial 4.0 Internacional (https://creativecommons.org/licenses/by-nc/4.0/deed.pt_BR), que permite copiar, distribuir e reproduzir em qualquer meio, bem como adaptar, transformar e criar a partir deste material, desde que para fins não comerciais e que você forneça o devido crédito aos autores e a fonte, insira um link para a Licença Creative Commons e indique se mudanças foram feitas. 


\section{Introdução}

As políticas públicas para transexualidades e travestilidades são uma temática recentemente trazida aos debates e produções científicas do Serviço Social brasileiro. Nesse cenário, refletir sobre a atuação do Serviço Social junto a essas populações, compreendendo de que forma vivenciam expressões da Questão Social e se inserem nas Políticas Sociais, apresenta-se indispensável e inadiável. Diferentemente do Conselho Federal de Psicologia que elaborou uma nota técnica sobre o processo transexualizador e demais formas de assistência às pessoas trans (CONSELHO FEDERAL DE PSICOLOGIA, 2013), o conjunto Conselho Federal de Serviço Social-Conselhos Regionais de Serviço Social (CFESS-CRESS) ainda não traçou parâmetros específicos à atuação junto a essa população.

Nesse sentido, esse artigo reúne uma pesquisa de produções teórico-práticas de diversos campos das Ciências Humanas e Sociais sobre transexualidades e travestilidades, em busca de discorrer a partir do Projeto Ético-Político-Profissional produzido no interior do Serviço Social brasileiro, possibilidades para atuação junto à população trans nos serviços de saúde. Nessa direção, o texto também é composto por uma pesquisa documental realizada no sítio do Conselho Federal de Serviço Social (CFESS). Os documentos tomados por referência nas discussões foram às resoluções n ${ }^{\circ}$ 615/2011, nº 489/2006 e n n 273/93 (Código de Ética Profissional do/a Assistente Social) do CFESS, a Lei no 8.662/93 (regulamentação do exercício profissional do Assistente Social no Brasil) e os Parâmetros de Atuação do Assistente Social na Saúde.

\section{As pessoas trans e os dilemas para acessar a saúde}

As transexualidades e travestilidades são experiências que revelam diversas possibilidades de construirse no gênero (BENEDETTI, 2005; BENTO, 2006; ROCON et al., 2017). Guilherme Almeida (2012) descreve uma aquarela de masculinidades na diversidade de possibilidades de modificações corporais e experiências de gênero vividas por homens transexuais. Da mesma forma, Benedetti (2005), Bento (2008) e Rocon et al. (2017), permitem falar sobre uma aquarela de feminilidades nas experiências de mulheres transexuais e travestis, desafiando olhar as identidades trans como "[...] processo tenso, aberto, marcado por disputas com alteridades que queremos eliminar e por outras que desejamos". (BENTO, 2008, p. 63).

Tal diversidade trans não é sinônima de autonomia e liberdade sobre seus corpos e vidas. Ao deslocarem-se dos gêneros atribuídos em nascimento na direção ao gênero desejado, sofrem com rebatimentos de expressões da Questão Social e inúmeras violações de direitos que poderão culminar no seu extermínio. Segundo relatório sobre assassinatos de Lésbicas, Gays, Bissexuais, Travestis, Transexuais e Transgêneros (LGBTs) realizado pelo Grupo Gay da Bahia, em 2016, o número total de assassinatos passou a 343, com 42\% do total correspondendo à morte de pessoas trans, apontando o Brasil como país que mais mata a população trans no mundo (GRUPO GAY DA BAHIA, 2016). Essa realidade exige analisar as vidas trans numa perspectiva de totalidade histórica, uma vez que, segundo Guilherme Almeida e Murta (2013, p. 396):

[...] indivíduos e grupos têm grande parte suas vidas condicionadas por determinantes de diversas naturezas: econômica, política, cultural e subjetiva. [...] Desta perspectiva, as trajetórias de vida de mulheres e homens transexuais constituem a síntese absolutamente singular de suas inserções de classe social, de gênero e "raciais", bem como de suas características culturais, etárias, de seus percursos afetivo-sexuais, entre outras.

As perseguições à população trans brasileira - transfobia e travestifobia - devem ser criticamente analisadas sob a perspectiva de totalidade. Bento (2006, p. 61) afirma que "[...] nas trajetórias de vida, podese notar que há um viés de classe social constante: todos são oriundos de camadas sociais excluídas. O fato de vivenciarem a experiência transexual, ou seja, de estarem fora das normas de gênero, torna estas pessoas duplamente excluídas". Isso influencia na inserção das pessoas no mercado de trabalho, refletindo no fato, por exemplo, de "[...] muitas mulheres transexuais da classe trabalhadora sobreviverem desde sempre com o trabalho sexual" (CONNEL; PEARSE, 2015, p. 218).

A divisão sexual do trabalho é um elemento importante para compreensão das desigualdades de gênero na sociedade capitalista, e, portanto, necessário à discussão. Connel e Pearse (2015) apresentam pesquisas que demonstram, em diferentes países e regiões do globo, desigualdades salariais e na ocupação de postos de trabalho entre homens e mulheres. Dentre os argumentos apresentados, destacam-se os fundamentados nos paradigmas biológicos: como justificar as desigualdades de condições no acesso a melhores salários e postos de trabalhos entre homens e mulheres, beneficiando os primeiros em virtude de uma suposta vantagem natural 
concedida por altos níveis de testosterona (CONNEL; PEARSE, 2015).

Connel e Pearse (2015, p. 93) contestam a compreensão das experiências no gênero como a-históricas e fixadas pela natureza, compreendendo-as como uma estrutura social: “[...] os corpos são afetados por processos sociais [...] pela distribuição de comida, costumes sociais, guerra, trabalho, esportes, urbanização, educação e medicina [...]. Todas essas influencias são estruturadas pelo gênero". Assim, as diferenças do gênero na vida social não são causalidades das diferenças biológicas, são distinções produzidas nos processos de trabalho, nos discursos, na produção científica, nas diferentes formas de educação, práticas disciplinares, que produzem desigualdades inerentes aos processos sociais capitalistas. Há diversas formas de disciplinar os corpos produzindo feminilidades submissas e as masculinidades dominantes, a divisão do trabalho, as relações familiares, a medicina, a escola e os esportes são importantes exemplos de instituições (re)produtoras das desigualdades de gênero da infância à fase adulta segundo as autoras.

No capitalismo as desigualdades de produção da vida material no gênero significam expropriar mais, explorar ainda mais as mulheres. Essa exploração parece manter-se presente após a transição nos gêneros realizada por pessoas transexuais. Schilt e Wiswall (2008 apud CONNEL; PEARSE, 2015, p. 217), demonstram que nos Estados Unidos, "[...] homens transexuais são eventualmente mais bem pagos após a transição do que antes, enquanto mulheres transexuais perdem, em média, um terço da renda".

As relações de gênero na contemporaneidade se estruturam num binarismo de gênero que reproduz a ideia de que as desigualdades nos gêneros são reflexos das diferenças biológicas dos corpos, especificamente as genitálias (BENTO, 2006), e que esses gêneros se complementam a partir de uma heterossexualidade compulsória, uma vez que a "[...] ordem social contemporânea se estrutura de forma que no dualismo hetero/ homo, a heterossexualidade seja naturalizada e compulsória". (FROEMMING; IRINEU; NAVAS, 2010, p. 167).

As pessoas trans, em sua diversidade, podem divergir das normas de gênero e sexualidade na medida em que se constroem destoando da matriz binária e heterossexual para os gêneros. Seus corpos desmentem a suposta estabilidade dos gêneros pela natureza ao transitarem entre os gêneros. Para Connel e Pearse (2015, p. 211), a diversidade de gênero é "[...] uma das provas mais dramáticas da importância dos processos sociais no gênero, e uma contraprova do essencialismo biológico bem conhecida". Ao resistirem essas normas hegemônicas, suas vidas são transformadas em abjetas. Segundo Froemming, Irineu e Navas (2010, p. 166), “[...] a linha de inteligibilidade do humano é pensada a partir do 'corpo - gênero - sexualidade' e dos pólos masculino e feminino, e na relação destes com seus opostos, dada assim também a nossa capacidade de compreensão da existência do outro. Ou o sujeito é isso ou é aquilo". Num perverso processo de desumanização de suas vidas, a população trans vai perdendo suas famílias, seus empregos, sendo excluída do acesso às políticas sociais, deixadas para morrer pela discriminação, preconceito, e principalmente pela desresponsabilizarão do Estado sobre suas vidas - que em tempos de neoliberalismo, valora negativamente as diferenças e impõe uma responsabilização individual dos sujeitos sobre si.

Em se tratando da política de saúde, percebem-se uma seletividade no acesso por desrespeito ao nome social, discriminação, e no caso do processo transexualizador do Sistema Único de Saúde (SUS) pelo processo de diagnóstico. Duarte (2014a) aponta as várias formas de discriminação, preconceito e marginalização reproduzidas por profissionais da saúde como barreira ao acesso dos serviços de saúde pela população LGBT. Mello et al. (2011) indicou que entre a população LGBT, as pessoas trans encontram maiores barreiras para acessar a política de saúde, por buscarem serviços específicos como o processo transexualizador, e pelos episódios de trans/travestifobia somadas à discriminação por outros marcadores sociais de diferença. Romano (2008) evidenciou o desrespeito ao nome social e as discriminações como provocadores de resistência na busca por serviços de saúde e de abandono de consultas ou tratamentos médicos em andamento.

Rocon, Sodré e Rodrigues (2016) e Rocon et al. (2016; 2017) também apontam o diagnóstico de transexualismo e a patologização das identidades de gênero trans como promotores de seletividade nos serviços oferecidos no Processo Transexualizador. Os autores identificam uma lacuna nos fundamentos do diagnóstico que tem sido preenchida pelo que Bento (2006) denominou como transexuais de verdade - que melhor reproduzem no corpo e nas performances de gênero os estereótipos de masculinidade e feminilidade hegemonicamente estabelecidos a partir do binarismo do gênero e da heterossexualidade compulsória, restringindo o acesso aos serviços de saúde a diversas pessoas trans que não se enquadram em determinados padrões estéticas e comportamentais de masculinidade e feminilidade.

Ao ser privada do acesso à saúde, a população trans fica fadada aos riscos de sofrimento, adoecimento e morte, uma vez que para a construção do corpo em sintonia com o gênero desejado, em busca da humanização de seus corpos e vidas, vão lançando mão de recursos como silicone industrial, hormônios sem atenção e o cuidado do acompanhamento médico, em alguns casos podem chegar até ao suicídio (BENTO, 2006; CONNEL; PEARSE, 2015; ROMANO, 2008). Rocon et al. (2016, p. 2524), nessa perspectiva, apontam que: 
A seletividade no acesso ao Processo Transexualizador do SUS promovida pelo diagnóstico precisa continuar sendo discutida. Ainda que a patologização signifique uma concessão estratégica, a Constituição Federal de 1988 não condiciona o acesso à saúde no SUS pela existência de uma patologia prévia, e esse foco na saúde pela negação da doença têm impedido pessoas trans de acessarem serviços públicos de saúde para assistência e cuidado profissional na modificação de seus corpos.

Os autores problematizam a noção de concessão estratégica em relação à patologização das identidades de gênero trans presente nas discussões pelo movimento social como forma de garantir o acesso à saúde. Destacam que o SUS constitucional, conciliado com os princípios da Reforma Sanitária, além de universal, não supõe a existência de uma patologia prévia como condicionante ao acesso à saúde, e assim, que a luta pela saúde da população trans não pode ser desconectada da luta pela efetivação do SUS, somente um sistema único, público e universal pode garantir a saúde trans no Estado brasileiro.

\section{Notas sobre o trabalho profissional no Processo Transexualizador}

Os procedimentos transgenitalizadores foram autorizados no Brasil em 1997 pelo Conselho Federal de Medicina (CFM). Em 2008, o Ministério da Saúde instituiu o Processo Transexualizador do SUS pela Portaria 1.707, beneficiando mulheres transexuais (BRASIL, 2008). No ano de 2013, a partir de uma redefinição através da Portaria 2.803, foi garantido o acesso a homens transexuais e travestis. Atualmente são oferecidos os serviços de hormonioterapia, cirurgias de transgenitalização, mastectomia, histerectomia, plástica mamária, tireoplastia, além de acompanhamentos clínico, psicológico e social (BRASIL, 2013).

Todavia, existem desafios à efetivação desse programa de saúde tanto no aprimoramento de técnicas e protocolos clínicos, como no preparo das equipes multiprofissionais às intervenções humanizadas. Bento (2006), Borba (2016) e Rocon et al. (2016, 2017) apresentam narrativas de pessoas trans sobre desrespeito aos nomes sociais, atendimentos desumanizados, dificuldades financeiras e os desgastes pela intensa rotina de consultas, etc. na busca por serviços transexualizadores no SUS. Segundo Connel e Pearse (2015, p. 217):

Não há nada bonito na mudança de gênero; são medidas drásticas com resultados severos. Embora atenção da mídia e a dos estudiosos tenham enfocado obsessivamente a cirurgia, esta é a única parte do tratamento médico, o qual é apenas uma parte da transição. Uma enorme quantidade de outras tarefas é necessária. Isso inclui levantar fundos; ter apoio pessoal, cuidados pós-operatórios, documentação legal; encontrar moradia; lidar com crises de relacionamentos; lidar com locais de trabalho ou arranjar trabalho; lidar com mudanças corporais; obter reconhecimento social; lidar com a hostilidade. Qualquer um desses fatores pode se tornar central.

As autoras narram uma série de fatores inerentes à transição no gênero, que em sua maioria, deslocam-se do campo da intervenção médica às relações sociais, compreendendo família, amigos, relacionamentos, mercado de trabalho, moradia, discriminação e documentação legal como determinantes do bem estar social da população trans. Assim, identifica-se um rico campo para intervenção do Serviço Social no uso de suas atribuições privativas.

Desde 1997 o Serviço Social compõe a equipe multiprofissional do processo transexualizador (CONSELHO FEDERAL DE MEDICINA, 1997). O Serviço Social é uma profissão especializada, inserida na divisão sociotécnica do trabalho, cuja especificidade - prestação de serviços importantes aos processos de reprodução das relações sociais - possui na questão social matéria prima de seu processo de trabalho. (IAMAMOTO, 2014a; 2014b). No trabalho em saúde, Duarte (2014b, p. 100) aponta o usuário como “[...] o objeto de trabalho, mas é também um agente", apresentando o usuário dos serviços de saúde como protagonista na produção do seu processo de saúde.

Todo processo de trabalho é regido por uma teleologia, tornando "[...] fundamental que os profissionais [...] desenvolvam habilidades para aplicação de seus instrumentos de trabalho que possibilitem uma análise crítica e a transformação do processo de trabalho em que estão inseridos". (DUARTE, 2014b, p. 96). A condição de trabalhador assalariado e a dependência dos contratantes do serviço social enquanto força de trabalho especializada, na organização e condições para a realização do processo de trabalho, impõem limites ao exercício profissional, uma contradição entre interesses dos contratantes e o dos usuários, e uma autonomia relativa no exercício profissional (IAMAMOTO, 2014a).

No processo transexualizador, por exemplo, nos termos da Resolução CFM nº 1.955/2010, o Serviço Social é reconhecido membro da equipe profissional responsável por selecionar pelo processo de diagnóstico, os(as) pacientes que terão acesso aos serviços transexualizadores (CONSELHO FEDERAL DE MEDICINA, 2010). O Serviço Social, enquanto profissão da saúde, não emite diagnóstico nosológico em seu processo de trabalho, no entanto, se considerarmos como estratégica a participação do Assistente Social no processo transexualizador assim como em 
nos demais equipamentos, programas e políticas de saúde, poderemos aventar que no exercício de sua autonomia relativa pelo seu projeto ético-político-profissional, poderá avançar na luta contra a seletividade dos serviços de saúde. Nessa direção esse texto avança sobre as possibilidades de trabalho do serviço social sobre eixos determinantes no acesso à saúde da população trans, compreendendo como Veloso (2014), a dimensão técnico-instrumental do Serviço Social como condição para realização e alcance das finalidades do processo de trabalho.

\section{A defesa do nome social e o combate as trans-travestifobias}

A auto atribuição de um novo nome compõe o trânsito no gênero (BENEDETTI, 2005; ROCON et al., 2016, 2018). Segundo Bento (2006, p. 57) o nome próprio “[...] funciona como uma interpelação que recoloca, que ressuscita a posição de gênero da qual luta pra sair". Para a autora, o uso do nome atribuído ao nascimento se equipara aos insultos como veado, sapatão, macho-fêmea também vivenciados por outras LGBTs. Essa e outras formas de discriminação no cotidiano dos serviços de saúde tem produzido abandono de tratamentos e resistência em buscar serviços públicos de saúde (ROCON et al., 2016, 2018; ROMANO, 2008). O Quadro 1 norteia Assistentes Sociais sobre essas questões.

\section{Quadro 1 - Defesa do Nome Social e o combate à discriminação}

\begin{tabular}{|c|c|c|}
\hline \multirow[t]{2}{*}{ A defesa do Nome Social } & $\begin{array}{l}\text { Resolução CFESS no } 615 \text {, de } 8 \\
\text { de setembro de } 2011 .\end{array}$ & $\begin{array}{l}\text { "Dispõe sobre a inclusão e uso do nome social da assistente social } \\
\text { travesti e do(a) assistente social transexual nos documentos de } \\
\text { identidade profissional." }\end{array}$ \\
\hline & $\begin{array}{l}\text { Resolução CFESS n }{ }^{\circ} 489 \text {, de } 3 \\
\text { de junho de } 2006 .\end{array}$ & $\begin{array}{l}\text { "Estabelece normas vedando condutas discriminatórias ou } \\
\text { preconceituosas, por orientação e expressão sexual por pessoas } \\
\text { do mesmo sexo, no exercício profissional do assistente social, } \\
\text { regulamentando princípio inscrito no Código de Ética Profissio- } \\
\text { nal." }\end{array}$ \\
\hline \multirow[t]{3}{*}{$\begin{array}{l}\text { Combate à discrimina- } \\
\text { ção transfóbicas e } \\
\text { travestifóbicas }\end{array}$} & \multirow[t]{3}{*}{$\begin{array}{l}\text { Código de Ética do/a Assistente } \\
\text { Social-Resolução CFESS n² 273, } \\
\text { de } 13 \text { de março de } 1993 .\end{array}$} & $\begin{array}{l}\text { "Exercício do Serviço Social sem ser discriminado/a, nem discri- } \\
\text { minar, por questões de inserção de classe social, gênero, etnia, } \\
\text { religião, nacionalidade, orientação sexual, identidade de gênero, } \\
\text { idade e condição física." }\end{array}$ \\
\hline & & $\begin{array}{l}\text { "Empenho na eliminação de todas as formas de preconceito, in- } \\
\text { centivando o respeito à diversidade, à participação de grupos so- } \\
\text { cialmente discriminados e à discussão das diferenças;" }\end{array}$ \\
\hline & & $\begin{array}{l}\text { "Denunciar, no exercício da Profissão, às entidades de organiza- } \\
\text { ção da categoria, às autoridades e aos órgãos competentes, casos } \\
\text { de violação da Lei e dos Direitos Humanos, quanto a: corrupção, } \\
\text { maus tratos, torturas, ausência de condições mínimas de sobre- } \\
\text { vivência, discriminação, preconceito, abuso de autoridade indi- } \\
\text { vidual e institucional, qualquer forma de agressão ou falta de } \\
\text { respeito à integridade física, social e mental do/a cidadão/cida- } \\
\text { dã;" }\end{array}$ \\
\hline
\end{tabular}

Fonte: Elaborado pelos autores com base em Conselho Federal de Serviço Social (2006, 2011)e Brasil (2012).

A Resolução CFESS nº 615, de 8 de setembro de junho de 2011, não trata especificamente do nome social para usuárias(os), no entanto, em suas considerações, a resolução pontua:

É objetivo do CFESS a construção de uma sociedade radicalmente justa e democrática sem preconceitos de origem, raça, etnia, sexo, orientação sexual, identidade de gênero, cor, idade ou quaisquer outras formas de discriminação, em consonância com o Código de Ética do(a) Assistente Social; Considerando que os direitos à livre orientação sexual e à livre identidade de gênero constituem direitos humanos de lésbicas, gays, bissexuais, travestis e transexuais (LGBT), e que a sua proteção requer ações efetivas das entidades 
do Serviço Social no sentido de assegurar o pleno exercício da cidadania da população LGBT (lésbicas, gays, bissexuais, travestis e transexuais); Considerando que toda pessoa tem direito ao tratamento correspondente a sua identidade de gênero. (CONSELHO FEDERAL DE SERVIÇO SOCIAL, 2011).

Portanto, é explicitado o posicionamento do CFESS em favor do direito universal a livre expressão de gênero. O CFESS também lançou a Resolução n 489 , de 3 de junho de 2006, que veda condutas discriminatórias junto à população LGBT por Assistentes Sociais, em sintonia com os Princípios Fundamentais do Código de Ética Profissional (BRASIL, 2012). A partir dos recortes apresentados no Quadro 1, percebe-se ser dever $\mathrm{da}(\mathrm{o})$ Assistente Social denunciar aos órgãos competentes as violações dos direitos humanos e empenhar-se na eliminação de todas as formas de preconceito. E preciso considerar que o(a) Assistente Social desenvolve seu trabalho de forma coletiva, junto a categorias profissionais que nem sempre congregam valores como liberdade, equidade e justiça social. $\mathrm{O}(\mathrm{a})$ profissional, no uso de sua dimensão pedagógica e de seus instrumentais teórico-práticos poderá vislumbrar junto aos demais profissionais e usuários no processo de trabalho em saúde, desconstruir a naturalização do binarismo de gênero e da heterossexualidade compulsória, problematizando a trans-travestifobia, produzido hegemonia em favor da garantia do acesso à saúde a toda população com equidade e integralidade.

\section{Os dilemas do diagnóstico de transexualismo}

A Resolução CFM n ${ }^{0}$ 1.955/2010 estabelece que "[...] a seleção dos pacientes para cirurgia de transgenitalismo obedecerá à avaliação de equipe multidisciplinar constituída por médico psiquiatra, cirurgião, endocrinologista, psicólogo e assistente social'. (CONSELHO FEDERAL DE MEDICINA, 2010, grifo nosso). Como dito anteriormente, diagnóstico nosológico não é objeto ou produto do processo de trabalho do Assistente Social, e que tal procedimento tem sido fator de seletividade do acesso à saúde.

Rocon et al. (2016, p. 2524) advertem que o diagnóstico médico não se isenta das normas sociais, apontando que "[...] numa sociedade cujas normas predominantes para a inteligibilidade dos corpos residem no gênero binário e na heteronormatividade, todos os corpos inadequados a esse padrão poderão ser considerados doentes". Tal diagnóstico não é a-histórico, é forjado em uma sociedade cuja sociabilidade é construída na produção de opressão e exploração, nesse sentido, não identifica doentes, mas sim, cria doentes, produz doenças e exclui as pessoas trans das relações sociais.

Rocon et al. (2018) identificaram que apesar de reconhecido como procedimento importante, as cirurgias de mudanças de sexo não são destacadas em relação às demais necessidades de intervenção nos corpos (hormonioterapia e demais cirurgias) pelas pessoas trans. Apresentando-se como

[...] a importância do Serviço Social brasileiro de se apropriar teórica, científica e politicamente das necessidades advindas das expressões da questão social experimentadas pela população trans $[$...]

tão importantes elementos como mudança de nome, acolhimento profissional, dentre outros fatores, que somados a realidade de inúmeras expressões da questão social vividas por essa população, supõe que o Assistente Social se torna um profissional estratégico nesse programa, não para diagnosticar como requerem as normativas, mas sim lutar por outra realidade social onde caiba a população trans. Especificamente no processo transexualizador, aqui apontamos para o desenvolvimento do trabalho junto às famílias, redes socioassistenciais e a construção de uma consciência sanitária como profícuo campo de intervenção.

\section{Trabalhando com família e nas redes socioassistenciais.}

As trans-travestifobias, ora internalizadas ora incidindo sobre as famílias de pessoas trans, são elementos responsáveis por fragilizar ou romper os laços familiares. Ainda permeia no imaginário social a responsabilização das famílias sobre as sexualidades da prole, onde, desvios no gênero e na sexualidade são compreendidos como fracasso dos pais na educação dos filhos. Isso se soma aos muitos apontamentos culpabilizadores em direção às famílias que abandonam seus entes LGBTs, esvaziados de uma perspectiva crítica capaz de compreender que essas famílias também são alvos de constrangimento e opressão pela homofobia, transfobia e travestifobia. 
Assim, a família torna-se um ponto chave na intervenção profissional, não numa perspectiva familista de "[...] máxima designação de obrigações à unidade familiar" (ALVES; MIOTO, 2015, p. 209), preenchendo o vácuo deixado pelo Estado na promoção de políticas sociais - mas compreendo-as como parte dos processos de transição no gênero de seus membros trans, bem como, na superação da transfobia e travestifobia, buscando "[...] intervenções que contribuam para reinscrever a família como usuária e não somente cuidadora, reivindicado o papel central do Estado na oferta de proteção social". (ALMEIDA, C. C. L., 2014, p. 190-191). Mioto (2004, p. 10, grifo nosso) aponta seis importantes ações a serem desenvolvidas no trabalho com famílias:

As ações sócio-educativas estão relacionadas àquelas que, através da informação, da reflexão ou mesmo da relação, visam provocar mudanças (valores, modos de vida). As ações sócio-terapêuticas são desenvolvidas diante de situações de sofrimento das famílias, expresso nas suas relações ou pelos seus membros, com a intenção de alterar esta situação. As ações periciais são aquelas que, através do estudo e da avaliação das situações familiares, visam à emissão de um parecer social para outrem. As ações sócio-assistenciais se relacionam a toda ação de provimento e de sustentação para atendimento de necessidades das famílias usuárias. As ações de acolhimento e apoio sócio-institucional consistiria, como o próprio nome indica, no acolhimento e apoio e na articulação de recursos através da ativação, integração e modificação das redes sociais e de serviços para atender as demandas.

Mioto (2004) oferece importantes indicações de como cuidar da saúde das pessoas trans intervindo sobre suas famílias, desde a identificação das necessidades e mobilização da rede de serviços socioassistenciais para saná-las, a utilização de estratégias qua auxiliem as famílias nos processos de desconstrução de ideais burgueses de família, gênero e sexualidade, buscando provocar a aceitação e acolhimento dos membros trans pela mudança de valores e modos de vida. As(os) assistentes sociais com inserção nesse campo de atuação, no uso de seu arsenal técnico-operativo, deverão buscar mediações que permitam identificar os recortes de raça, gênero, sexualidade e classe social onde se inserem as famílias, a fim de compreender de que forma as expressões da questão social interferem nas suas vidas e nas relações com seus membros trans.

Nessa direção, o Quadro 2 reúne recortes do Código de Ética Profissional, da Lei de Regulamentação da Profissão e dos Parâmetros de Atuação na Saúde que poderão nortear o trabalho profissional:

\section{Quadro 2 - Possibilidades de atuação no Processo Transexualizador Brasileiro}

\begin{tabular}{|c|c|c|}
\hline \multirow{4}{*}{$\begin{array}{l}\text { Em defesa da autonomia e } \\
\text { da liberdade das pessoas } \\
\text { trans sobre seus corpos e } \\
\text { vidas. }\end{array}$} & \multirow{4}{*}{$\begin{array}{l}\text { Código de Ética do/a Assis- } \\
\text { tente Social - Resolução } \\
\text { CFESS } \mathrm{n}^{\circ} 273 \text {, de } 13 \text { de } \\
\text { março de } 1993 \text {. }\end{array}$} & $\begin{array}{l}\text { "Reconhecimento da liberdade como valor ético central e das deman- } \\
\text { das políticas a ela inerentes - autonomia, emancipação e plena expan- } \\
\text { são dos indivíduos sociais". }\end{array}$ \\
\hline & & $\begin{array}{l}\text { "Defesa intransigente dos direitos humanos e recusa do arbítrio e do } \\
\text { autoritarismo". }\end{array}$ \\
\hline & & $\begin{array}{l}\text { "Ampliação e consolidação da cidadania, considerada tarefa primor- } \\
\text { dial de toda sociedade, com vistas à garantia dos direitos civis sociais } \\
\text { e políticos das classes trabalhadoras". }\end{array}$ \\
\hline & & $\begin{array}{l}\text { "Posicionamento em favor da equidade e justiça social, que assegure } \\
\text { universalidade de acesso aos bens e serviços relativos aos programas } \\
\text { e políticas sociais, bem como sua gestão democrática". }\end{array}$ \\
\hline \multirow[t]{4}{*}{$\begin{array}{l}\text { Fortalecimento da autono- } \\
\text { mia e da liberdade. }\end{array}$} & \multirow[t]{4}{*}{$\begin{array}{l}\text { Lei } n^{\circ} 8.662 \text {, de } 7 \text { de junho } \\
\text { de } 1993 .\end{array}$} & $\begin{array}{l}\text { "III - encaminhar providências, e prestar orientação social a indiví- } \\
\text { duos, grupos e à população". }\end{array}$ \\
\hline & & $\begin{array}{l}\text { "V - orientar indivíduos e grupos de diferentes segmentos sociais no } \\
\text { sentido de identificar recursos e de fazer uso dos mesmos no atendi- } \\
\text { mento e na defesa de seus direitos". }\end{array}$ \\
\hline & & $\begin{array}{l}\text { "VI - planejar, organizar e administrar benefícios e Serviços So- } \\
\text { ciais". }\end{array}$ \\
\hline & & $\begin{array}{l}\text { "XI - realizar estudos sócio-econômicos com os usuários para fins de } \\
\text { benefícios e serviços sociais junto a órgãos da administração pública } \\
\text { direta e indireta, empresas privadas e outras entidades." }\end{array}$ \\
\hline
\end{tabular}


Contribuições dos Parâmetros de Atuação na Saúde

\begin{tabular}{|c|c|}
\hline \multirow[t]{6}{*}{ Ações Socioassistenciais } & $\begin{array}{l}\text { "construir o perfil socioeconômico dos usuários, evidenciando as condições determinantes e } \\
\text { condicionantes de saúde" }\end{array}$ \\
\hline & "conhecer a realidade do usuário por meio da realização de visitas domiciliares" \\
\hline & "conhecer e mobilizar a rede de serviços, tendo por objetivo viabilizar os direitos sociais" \\
\hline & $\begin{array}{l}\text { "fortalecer os vínculos familiares, na perspectiva de incentivar o usuário e sua família a se tornarem } \\
\text { sujeitos do processo de promoção, proteção, prevenção, recuperação e reabilitação da saúde" }\end{array}$ \\
\hline & $\begin{array}{l}\text { "formular estratégias de intervenção profissional e subsidiar a equipe de saúde quanto as informa- } \\
\text { ções sociais dos usuários" }\end{array}$ \\
\hline & "buscar garantir o direito do usuário ao acesso aos serviços" \\
\hline \multirow{7}{*}{$\begin{array}{l}\text { Ações de articulação com a } \\
\text { Equipe de Saúde }\end{array}$} & "esclarecer as suas atribuições e competências para os demais profissionais da equipe de saúde" \\
\hline & $\begin{array}{l}\text { "construir e implementar, junto com a equipe de saúde, propostas de treinamento e capacitação do } \\
\text { pessoal técnico-administrativo com vistas a qualificar as ações administrativas que tem interface } \\
\text { com o atendimento ao usuário" }\end{array}$ \\
\hline & $\begin{array}{l}\text { "incentivar e participar junto com os demais profissionais de saúde da discussão do modelo } \\
\text { assistencial e da elaboração de normas, rotinas e da oferta de atendimento da unidade, tendo por } \\
\text { base os interesses e demandas da população usuária" }\end{array}$ \\
\hline & $\begin{array}{l}\text { "atender o usuário e sua família, desde a entrada do mesmo na unidade por meio de rotinas de } \\
\text { atendimento construídas com a participação da equipe de saúde" }\end{array}$ \\
\hline & "planejar, executar e avaliar com a equipe de saúde ações que assegurem a saúde enquanto direito" \\
\hline & $\begin{array}{l}\text { "avaliar as questões sociofamiliares que envolvem o usuário e/ou sua família, buscando favorecer a } \\
\text { participação de ambos no tratamento de saúde proposto pela equipe" }\end{array}$ \\
\hline & $\begin{array}{l}\text { "realizar a notificação, junto com a equipe multiprofissional, frente a uma situação constatada e/ou } \\
\text { suspeita de violência aos segmentos já explicitados anteriormente, às autoridades competentes, } \\
\text { bem como verificar as providências cabíveis, considerando sua autonomia e o parecer social do } \\
\text { assistente social" }\end{array}$ \\
\hline \multirow[t]{5}{*}{ Ações Socioeducativas } & $\begin{array}{l}\text { "sensibilizar os usuários acerca dos direitos sociais, princípios e diretrizes do SUS, rotinas } \\
\text { institucionais, promoção da saúde e prevenção de doenças por meio de grupos socioeducativos" }\end{array}$ \\
\hline & $\begin{array}{l}\text { "democratizar as informações da rede de atendimento e direitos sociais por meio de ações de } \\
\text { mobilização na comunidade" }\end{array}$ \\
\hline & $\begin{array}{l}\text { "socializar informações e potencializar as ações socioeducativas desenvolvendo atividades nas } \\
\text { salas de espera" }\end{array}$ \\
\hline & "realizar atividades em grupos com os usuários e suas famílias, abordando temas de seu interesse" \\
\hline & $\begin{array}{l}\text { "elaborar e/ou divulgar materiais socioeducativos como folhetos, cartilhas, vídeos, cartazes e outros } \\
\text { que facilitem o conhecimento e o acesso dos usuários aos serviços oferecidos pelas unidades de } \\
\text { saúde e aos direitos sociais em geral" }\end{array}$ \\
\hline
\end{tabular}

Fonte: Elaborado pelos autores com base em Brasil (2012)e Conselho Federal de Serviço Social (2010).

As ações apontadas por Mioto (2004) e os substrato dos dispositivos ético-políticos-profissionais expostos no Quadro 2 revelam possibilidades do exercício profissional do serviço social no processo transexualizador, como a desconstrução das normas hegemônicas para gênero e sexualidade junto às famílias trans através de ações socioeducativas, e quando necessárias ações socioterapêuticas junto à psicologia, a fim de reestabelecer laços familiares e inserir as famílias como usuárias nos processos de cuidado. Nessa direção, somam-se ações periciais e sócioassistenciais, com visitas domiciliares, análises socioeconômicas, trabalhos com grupos, etc., identificando a realidade na qual se inserem usuários e familiares, bem como condicionantes e determinantes sociais de seus processos de saúde-adoecimento-cuidado, acionando as redes assistenciais com fins de acesso a direitos sociais, previdenciários, habitacionais, trabalhistas, etc. 
$\mathrm{O}$ trabalho com a rede será indissociável das ações profissionais junto a indivíduos e famílias nos processos transexualizadores brasileiros. Para Almeida e Santos (2014, p. 223), “[...] é importante ressaltar que programas complexos que integram a política de saúde e outras políticas sociais, como são o caso do processo transexualizador, só lograrão na medida em que incorporem progressivamente uma perspectiva intersetorial". Assim, inserir e garantir a permanência de pacientes e famílias nos processos transexualizadores, irão requerer ações de acolhimento e apoio socioinstitucional para que as redes sejam construídas, acionadas, ampliadas ou modificadas a fim de responder as demandas por acesso com direitos sociais.

O trabalho profissional nesse programa se apresenta como lugar privilegiado para despertar/promover uma consciência sanitária nos pacientes e familiares. Um conceito do sanitarista Giovanni Berlinguer, que, partindo da Reforma Sanitária Italiana, introduz a ideia de ações individuais e coletivas em direção a alcançar direitos muitas vezes sufocados, por uma tomada de consciência sobre a saúde como direito (FLEURY, 2015). São muitos os desafios para efetivar o Processo Transexualizador do SUS como um programa universal, integral, equânime e com participação social. Primeiro porque ele não está descolado da realidade de desmontes, precarização das relações de trabalho, subfinanciamento, privatização e desestatização que avanços da política neoliberal têm promovido na saúde pública brasileira. Segundo, por se tratar de um programa que esbarra nas normas hegemônicas que regulam gêneros e sexualidades sob padrões binários e heteronormativos, tornando os programas seletivos como mostram Rocon, Sodré e Rodrigues (2016), Rocon et al. (2016; 2017), Borba (2016) e Bento (2006).

Nesse sentido, como argumentam Rocon et al. (2016), não será possível lutar pelo sucesso do Processo Transexualizador do SUS descolado da luta pela defesa e efetivação do SUS constitucional, pautada nos princípios e valores empreendidos pelo movimento da Reforma Sanitária brasileira. Connel e Pearse (2015, p. 219) advertem que muitas mulheres transexuais não assumem nenhuma bandeira política, isso porque, a transição no gênero acontece em meio a inúmeras contradições sociais que consomem "[...] um bom tanto de energia apenas para que seja possível manter-se íntegra". As autoras permitem identificar a importância das ações do Serviço Social articularem-se profundamente, uma vez que a construção da consciência sanitária solicitará um conjunto de ações a fim de possibilitar condições para a inserção das pessoas trans e seus familiares nos processos coletivos de lutas sociais e resistências em defesa do SUS.

\section{Considerações Finais}

Embora o conjunto CFESS-CRESS não tenha construído uma Nota Técnica a fim de orientar as(os) Assistentes Sociais brasileiros(as) atuantes no Processo Transexualizador do SUS, essas orientações podem ser encontradas no conjunto de dispositivos ético-políticos da profissão. Esse artigo elaborou uma síntese das formulações do conjunto CFESS-CRESS articulada às discussões teóricas do campo, apontando combate a trans-travestifobia nos serviços de saúde, a defesa do nome social, o trabalho com famílias, a construção de redes socioassistenciais e o despertar da consciência sanitária como eixos componentes de um rico campo para atuação profíssional e evidenciam a importância do Serviço Social brasileiro de se apropriar teórica, científica e politicamente das necessidades advindas das expressões da questão social experimentadas pela população trans, e também, das dificuldades em se criar, efetivar e garantir o acesso universal as políticas e programas sociais necessárias a essa população.

\section{Referências}

ALMEIDA, C. C. L. Saúde e cuidado: elementos para o trabalho com famílias. In: DUARTE, M. J. O.; ALMEIDA, C. C. L.; MONNERAT, G. L.; SOUZA, R. G. de (Org.). Politica de saúde hoje: interfaces \& desafios no trabalho de assistentes sociais. Campinas: Papel Social, 2014a. p. 179-192.

ALMEIDA, G. 'Homens trans': novos matizes na aquarela das masculinidades? Estudos Feministas, Florianópolis, v. 20, n. 2, p. 513 523, maio/ago. 2012.

ALMEIDA, G.; MURTA, D. Reflexões sobre a possibilidade da despatologização da transexualidade e a necessidade da assistência integral à saúde de transexuais no Brasil. Sexualidad, Salud y Sociedad, Rio de Janeiro, n. 14, p. 380-407, ago. 2013.

ALMEIDA, G.; SANTOS, M. C. B. Intersetorialidade na efetivação do processo transexualizador do SUS: uma indispensável utopia. In: MONNERAT, G. L.; ALMEIDA, N. L. T. de; SOUZA, R. G. de (Org.). A intersetorialidade na agenda das politicas sociais. Campinas: Papel Social, 2014. p. 203-228.

ALVES, F. L; MIOTO, R. C. T. O Familismo nos Serviços de Saúde: expressões em trajetórias assistenciais. Argumentum, Vitória, v. 7, n. 2, p. 208-220, jul./dez. 2015.

BENEDETTI, M. R. Toda feita: o corpo e o gênero das travestis. Rio de Janeiro: Garamond, 2005.

BENTO, B. A (re)invenção do corpo: sexualidade e gênero na experiência transexual. Rio de Janeiro: Garamond, 2006. 
BENTO, B. O que é transexualidade. São Paulo: Brasiliense, 2008.

BORBA, R. O (des)aprendizado de si: transexualidades, interação e cuidado em saúde. Rio de Janeiro: Hucitec, 2016.

BRASIL. Código de ética do/a assistente social. Lei 8.622/93 de regulamentação da profissão. 10. ed. rev. e atual. Brasília: Conselho Federal de Serviço Social, 2012. Disponível em: $<$ http://www.cfess.org.br/arquivos/CEP_CFESS-SITE.pdf $>$. Acesso em: 8 mar. 2017. . Ministério da Saúde. Portaria $n^{\circ} 1.707$, de 18 de agosto de 2008. Institui, no âmbito do Sistema Único de Saúde (SUS), o Processo Transexualizador, a ser implantado nas unidades federadas, respeitadas as competências das três esferas de gestão. Diário Oficial da União, Brasília, DF, 19 ago. 2008. Seção 1, p. 43. Disponível em: <http://bvsms.saude.gov.br/bvs/saudelegis/gm/2008/ prt1707_18_08_2008.html>. Acesso em: 03 mai. 2015.

. Ministério da Saúde. Portaria no 2.803 , de 19 de novembro de 2013. Redefine e amplia o Processo Transexualizador no Sistema Único de Saúde (SUS). Diário Oficial da União, Brasília, DF, 21 nov. 2013. Seção 1, p. 25-30. Disponível em: <http://bvsms.saude.gov.br/ bvs/saudelegis/gm/2013/prt2803_19_11_2013.html>.Acesso em: 03 mai. 2015.

CONNEL, R.; PEARSE, R. Gênero: uma perspectiva global. São Paulo: Nversos, 2015.

CONSELHO FEDERAL DE MEDICINA. Resolução nº 1.482, de 10 de setembro de 1997. Diário Oficial [da] República Federativa do Brasil, Brasília, DF, 19 set. 1997. Seção 1, p. 20994. Disponível em: <http://pesquisa.in.gov.br/imprensa/jsp/visualiza/ index.jsp?data=19/09/1997\&jornal=1\&pagina=208>. Acesso em: 8 mar. 1997.

. Resolução no 1.955, de 12 de agosto 2010. Diário Oficial da União, Brasília, DF, 3 set. 2010. Seção 1, p. 109-110. Disponível em:

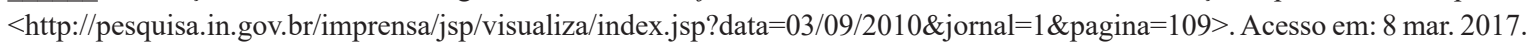

CONSELHO FEDERAL DE PSICOLOGIA. Nota técnica sobre o processo transexualizador e demais formas de assistência às pessoas trans. Brasília, 2013. Disponível em <https://site.cfp.org.br/wp-content/uploads/2013/09/Nota-t\%C3\%A9cnica-processoTrans.pdf $>$. Acesso em: 17 jul. 2018.

CONSELHO FEDERAL DE SERVIÇO SOCIAL. Parâmetros para atuação de assistentes sociais na Política de Saúde. Brasília, 2010. (Série Trabalho e Projeto Profissional nas Políticas Sociais, n. 2).

. Resolução n ${ }^{\circ}$ 489, de 3 de junho de 2006. Diário Oficial da União, Brasília, DF, 7 jun. 2006. Seção 1, p. 80. Disponível em:

$\overline{<\mathrm{http}: / / p e s q u i s a . i n . g o v . b r / i m p r e n s a / j s p / v i s u a l i z a / i n d e x . j s p ? j o r n a l=1 \& p a g i n a=80 \& d a t a=07 / 06 / 2006>. ~ A c e s s o ~ e m: ~} 8$ mar. 2017. . Resolução n ${ }^{\circ} 615$, de 8 de setembro de 2011. Diário Oficial da União, Brasília, DF, 9 set. 2011. Seção 1, p. 142. Disponível em:

$<$ http://pesquisa.in.gov.br/imprensa/jsp/visualiza/index.jsp?jornal=1\&pagina=142\&data=09/09/2011>. Acesso em: 8 mar. 2017.

DUARTE, M. J. O. Diversidade sexual, políticas públicas e direitos humanos: saúde e cidadania LGBT em cena. Temporalis, Rio de Janeiro, v. 14, n. 27, p. 77-98, jan./jun. 2014a.

. Processo de Trabalho em Saúde e Serviço Social: notas sobre o trabalho profissional no campo da saúde. In: DUARTE, M. J.

O. ; ALMEIDA, C. C. L. ; MONNERAT, G. L. ; SOUZA, R. G. de (Org.). Política de Saúde Hoje: Interfaces \& Desafios no Trabalho de Assistentes Sociais. Campinas: Papel Social, 2014b. p. 93-113.

FLEURY, S. Giovanni Berlinguer: socialista, sanitarista, humanista! Ciência \& Saúde Coletiva, Rio de Janeiro, v. 20, n. 11, p. 3553-3559, 2015. FROEMMING, C. N.; IRINEU, B. A.; NAVAS, K. Gênero e Sexualidade na pauta das políticas públicas no Brasil. Revista de Politicas Publicas, Maranhão, v. 1, p. 161-172, ago. 2010.

GRUPO GAY DA BAHIA. Relatório 2016: assassinatos de LGBTs no Brasil. 2016. Disponível em: <https:// homofobiamata.files.wordpress.com/2017/01/relatc3b3rio-2016-ps.pdf>. Acesso em: 6 fev. 2016.

IAMAMOTO, M. V. O Serviço Social em tempo de capital fetiche: capital financeiro, trabalho e questão social. 8. ed. São Paulo: Cortez, 2014a. IAMAMOTO, M. V. O Serviço Social na contemporaneidade: trabalho e formação profissional. 25. ed. São Paulo: Cortez, 2014 b.

MELLO, L. et al. Políticas de saúde para lésbicas, gays, bissexuais, travestis e transexuais no Brasil: em busca de universalidade, integralidade e equidade. Sexualidad, Salud y Sociedad, Rio de Janeiro, n. 9, p. 7-28, dez. 2011.

MIOTO, R. C. T. Trabalho com famílias: um desafio para assistentes sociais. Textos e Contextos, Porto Alegre, v. 3, n. 1, p. 1-15, dez. 2004. ROCON, P. C. et al. Dificuldades vividas por pessoas trans no acesso ao Sistema Único de Saúde. Ciência \& Saúde Coletiva, Rio de Janeiro, v. 21, n. 8, p. 2517-2526, 2016.

. (Trans)formações corporais: reflexões sobre saúde e beleza. Saúde e Sociedade, São Paulo, v. 26, n 2, p. 521-532, abr.jun. 2017. . O que esperam pessoas trans do Sistema Único de Saúde? Interface, Botucatu, v. 22, n. 64, p. 43-532, jan./mar. 2018.

ROCON, P. C.; SODRÉ, F.; RODRIGUES, A. Regulamentação da vida no processo transexualizador brasileiro: análise sobre a política pública. Revista Katálysis, Florianópolis, v. 19, n. 2, p. 260-269, jul./set. 2016.

ROMANO, V. F. As travestis no Programa Saúde da Família da Lapa. Saúde e Sociedade, São Paulo, v. 17, n. 2, p. 211-219, abr./jun. 2008. VELOSO, V. Condições de trabalho e dimensão técnico-operativa do Serviço Social. In: DUARTE, M. J. O.; ALMEIDA, C. C. L.; MONNERAT, G. L.; SOUZA, R. G. de (Org.). Política de saúde hoje: interfaces \& desafios no trabalho de assistentes sociais. Campinas: Papel Social, 2014. p. 115-133.

\section{Pablo Cardozo Rocon}

pablocardoz@gmail.com

Mestrado em Saúde Coletiva pela Universidade Federal do Espírito Santo (UFES)

Professor Assistente no Instituto de Saúde Coletiva da Universidade Federal de Mato Grosso (UFMT) 


\section{UFMT}

Av. Fernando Corrêa, 2367 - Boa Esperança

Cuiabá - Mato Grosso - Brasil

CEP: $78.060-900$

\section{Marco José de Oliveira Duarte}

marco.duarte@ufjf.edu.br

Doutorado em Serviço Social pelo Programa de Pós-Graduação em Serviço Social da Universidade do Estado do Rio de Janeiro (UERJ)

Professor Adjunto da Faculdade de Serviço Social e do Programa de Pós-Graduação em Serviço Social da Universidade Federal de Juiz de Fora (UFJF) e Professor do Programa de Pós-Graduação em Serviço Social da Universidade do Estado do Rio de Janeiro (UERJ)

\section{UFJF}

Rua José Lourenço Kelmer, s/n - São Pedro

Juiz de Fora - Minas Gerais - Brasil

CEP: $36.036-900$

\section{UERJ}

Rua São Francisco Xavier, 524, $9^{\circ}$ andar, bloco D, sala 9001 - Maracanã

Rio de Janeiro - Rio de Janeiro - Brasil

CEP: $20.550-013$

\section{Francis Sodré}

francisodre@uol.com.br

Doutorado em Saúde Coletiva pelo Programa de Pós-Graduação em Saúde Coletiva do Instituto de Medicina Social da Universidade do Estado do Rio de Janeiro (UERJ)

Professora Adjunta do Departamento de Serviço Social e do Programa de Pós-Graduação em Saúde Coletiva da Universidade Federal do Espírito Santo (UFES)

\section{UFES}

Av. Fernando Ferrari, 514 - Goiabeiras

Vitória - Espírito Santo - Brasil

CEP: 29.075-910

Agência financiadora

Não se aplica.

\section{Contribuições dos autores}

Pablo Cardozo Rocon participou da concepção, análise e sistematização dos dados, redação e revisão final. Marco José de Oliveira Duarte e Francis Sodré participaram da redação e revisão final. Os (as) autores(as) aprovaram a versão final apresentada.
Aprovação por Comitê de Ética e consentimento para participação

Não se aplica.

Consentimento para publicação

Não se aplica.

Conflito de interesses

Não há conflito de interesses. 